\title{
Parques, jardines y otras dotaciones. Su protección urbanística en Andalucía
}

\author{
Francisco López Menudo \\ Catedrático de Derecho Administrativo \\ Universidad de Sevilla
}

\begin{abstract}
SUMARIO: I. UNA IMPORTANTE INNOVACIÓN DE LA LOUA PARA LA PROTECCIÓN DE ZONAS VERDES Y OTRAS DOTACIONES URBANÍSTICAS.- II. DEPURACIÓN DE LOS CONCEPTOS O DEPENDENCIAS OBJETO DE LA "MODIFICACIÓN CUALIFICADA": A. Zonas verdes y Espacios libres. B. Dotaciones y equipamientos.- III. EN TORNO A LOS ESTÁNDARES ESTABLECIDOS POR LA LOUA: A. Un único estándar para todo el territorio (excluido el suelo no urbanizable). B. Los distintos estándares "de sector”.- IV. SOBRE EL CARÁCTER NO INTERCAMBIABLE DE ESTOS ESPACIOS.
\end{abstract}

\section{UNA IMPORTANTE INNOVACIÓN DE LA LOUA PARA LA PRO- TECCIÓN DE ZONAS VERDES Y OTRAS DOTACIONES UR- BANÍSTICAS}

Una de las novedades más significativas de la Ley 7/2002 de 17 de diciembre, de Ordenación Urbanística de Andalucía (LOUA), ha sido la especial protección que establece frente a la modificación de ciertos espacios y equipamientos que podemos englobar bajo el concepto de "dotaciones", sin perjuicio de las precisiones que haremos de este concepto más adelante. Se trata de una innovación realmente singular, no sólo por la importancia o intensidad de la previsión legal sino porque no tiene igual en el panorama del derecho urbanístico autonómico. El artículo 36 de la LOUA, referido al "régimen de la innovación de la ordenación establecida por los instrumentos de planeamiento", en su apartado 2.c.2르, dice lo siguiente:

"Las modificaciones que tengan por objeto una diferente zonificación o uso urbanistico de parques, jardines o espacios libres, dotaciones o equipamientos requerirán el dictamen favorable del Consejo Consultivo de Andalucía" 
Se trata, en suma, de la llamada "modificación cualificada" del planeamiento, en la que se exige la intervención del superior Órgano consultivo -no así en el caso de la revisión del $\mathrm{Plan}^{1}-$, con el alcance previsto en el precepto y la atribución de la competencia para su aprobación definitiva a un órgano superior (el titular de la Consejería de Obras Públicas y Transportes) distinto del que es competente para las modificaciones que pudiéramos denominar "ordinarias"2.

${ }^{1}$ Ciertamente, es regla ya muy asentada que el procedimiento "cualificado" sólo procede en los casos de modificación y no de "revisión" del Plan, dos conceptos de confines difusos como se deduce de la abundante jurisprudencia recaída al respecto. La distinción fue introducida por el Reglamento de Planeamiento (art. 154) y acogida por el artículo 126 de la Ley del Suelo, TR 1992. En la misma línea, el art. 36.1 de la LOUA subdivide la "innovación" en dos especies: la "revisión" (art. 37.1) y la "modificación" (art. 38.1), no contribuyendo precisamente a marcar la diferencia de una y otra puesto que considera como revisión no sólo la que afecta a la totalidad del territorio sino también la "revisión parcial" cuando justificadamente "se circunscriba a una parte, bien del territorio ordenado por el instrumento de planeamiento objeto de la misma, bien de sus determinaciones que formen un conjunto homogéneo, o de ambos a la vez" (art. 37.2), lo cual difumina la frontera entre una y otra figura.

Cabe recordar aquí la polémica doctrina que mantuvieron en su día los profesores GÓMEZ FERRER, R. y MUNOZ MACHADO, S., abogando el primero porque la garantía del procedimiento "cualificado" se siguiera tanto en las modificaciones como en las revisiones, al estimar el primero que no existía razón alguna que justificara la diferencia, teniendo en cuenta que el objeto de tal garantía era defender estos espacios del acoso de los especuladores, tesis que fue seguida por alguna sentencia del TS. El segundo sostuvo la imposibilidad de unificar la garantía pues, además de que la distinción legal entre revisión y modificación era muy clara, la revisión implica un replanteamiento de conjunto, la posible elección de un modelo territorial distinto, opinión que fue avalada por numerosa jurisprudencia y que al cabo es la que se ha impuesto.

No ha sido insensible el Consejo Consultivo de Andalucía al problema de fondo que subyace a esa polémica pues, ciertamente, es posible pensar que en la práctica se acometa en algún caso el cauce de la revisión para eludir el superior control que supone el procedimiento modificatorio cuando se trata de alterar zonas verdes. Y así, en la Memoria del Consejo del año 2000 éste sugirió a los distintos poderes de la Junta de Andalucía la posibilidad de que se dispusiera la extensión de su competencia a los casos de revisión del planeamiento, justificando su propuesta en el argumento de que "no acaba de entenderse el distinto tratamiento dado a modificación y revisión, que permite, además, el que baste con articular la modificación como revisión del Plan para evitar el dictamen del Consejo Consultivo". La sugerencia no fue recogida por la LOUA, que reserva el control consultivo sólo para los casos de modificación. Pero no estaba falta de razón dicha sugerencia pues tampoco hay que exacerbar la supuesta discrecionalidad del planificador a la hora de la revisión como si tuviera manos libres para hacer y deshacer lo que desee sin sometimiento a control alguno. Esa discrecionalidad se encuentra comprimida en buena medida por la "exigencia de racionalidad de las nuevas decisiones urbanísticas; por la valoración correcta de las situaciones fácticas; por la coherencia de la utilización del suelo con las necesidades objetivas de la comunidad..." (SSTS 20-7-2001, Ar. 275256; 19-9-1997, Ar. 6598), lo que viene a desmentir la tópica idea de que la revisión sea una operación que necesariamente exija hacer un "borrón y cuenta nueva" del territorio ordenado desde la más pura libertad. Ya veremos más adelante cómo la LOUA comprime la discrecionalidad del planificador de una manera notable, aun en los casos de revisión del Plan, según resulta del art. 36.2.a.2ª̣ .

${ }^{2}$ Vid. art. 5.3.d) en relación con el 13.2.a) del Decreto 193/2003 de 1 de julio por el que se regula el ejercicio de las competencias de la Administración de la Comunidad Autónoma de An- 
Debe notarse que el precepto no utiliza la fórmula tradicional "zonas verdes y espacios libres", que fue la contemplada en la Ley 8/1993 del Consejo Consultivo de Andalucía (que no hizo sino reproducir lo que al respecto establecieron la legislación urbanística estatal y la Ley Orgánica del Consejo de Es$\operatorname{tado}^{3}$ ), sino que añade las "dotaciones o equipamientos", lo que representa no un mero cambio terminológico sino un verdadero salto cualitativo, una ampliación de notable trascendencia.

En efecto, todas las opiniones doctrinales y jurisprudenciales que tradicionalmente se han venido suscitando en torno al tema en cuestión no han tenido más objeto que desentrañar las dudas acerca de si el concepto de zona verde se incluye o no en el de espacio libre o si son realidades físicas distintas; y la muy debatida cuestión de si algunos espacios o instalaciones concretos (paseos marítimos, ferias, zoológicos, aparcamientos...) forman parte o no de la categoría del "espacio libre". Pero lo que nunca ha estado en liza han sido los conceptos de "dotaciones y/o equipamientos", sencillamente porque estos espacios, dependencias o instalaciones, genéricamente considerados, nunca han sido objeto de una protección como la que ahora les otorga la LOUA. Las restantes leyes urbanísticas autonómicas siguen en este punto sin salirse del contexto de las zonas verdes y los espacios libres, bien considerando los espacios libres como categoría única y comprensiva de todos los terrenos verdes (Aragón, Murcia); o distinguiendo ambas categorías (Extremadura, Galicia, La Rioja, Madrid); o bien añadiendo a dichas categorías alguna precisión, más bien terminológica que sustancial, tal como la expresión "equipamientos deportivos" (Cataluña).

dalucía en materia de Ordenación del Territorio y Urbanismo. Este procedimiento "cualificado" de modificación del planeamiento tiene su origen en la Ley de Zonas Verdes de 2 de diciembre de 1963 que estableció los siguientes requisitos o trámites: Justificación de que la modificación se debe a razones de interés general; aprobación municipal con un quorum de 2/3 del Pleno de la Corporación; informe favorable de la Comisión Central de Urbanismo; informe favorable del Consejo de Estado; aprobación por el Consejo de Ministros.

${ }^{3} \mathrm{El}$ art. 16.8.d) de la citada Ley de creación del Consejo Consultivo de Andalucía, de 19 de octubre de 1993, dispuso que éste sería consultado preceptivamente en los procedimientos de "modificación de figuras de planeamiento que tengan por objeto una diferente zonificación o uso urbanístico de zonas verdes o espacios libres previstos en un plan”. Por su parte, la nueva y reciente Ley 4/2005 de 8 de abril, del Consejo Consultivo de Andalucía, recoge ya en su art. 17.10.e) las innovaciones de la LOUA sobre la intervención preceptiva del Consejo: "Modificación de figuras de planeamiento que tengan por objeto una diferente zonificación o uso urbanístico de parques, jardines o espacios libres, dotaciones o equipamientos, previstos en un plan, así como los supuestos de suspensión de instrumentos de planeamiento que competen al Consejo de Gobierno". 
Hay que insistir en resaltar la trascendencia de esta nueva regulación del tema en la LOUA, relevancia que puede concretarse en los puntos siguientes:

a) Un considerable aumento de las dotaciones urbanísticas cuya modificación queda sujeta al dictamen preceptivo del Consejo Consultivo de Andalucía. Desde el punto de vista cuantitativo podría decirse que los nuevos espacios protegidos que ahora se adicionan a las tradicionales "zonas verdes y espacios libres" son de mayor volumen que estos últimos y, en todo caso, más susceptibles de ser alterados con ocasión de la modificación de los planes.

b) No cabe olvidar que dicho dictamen, además de preceptivo tiene carácter vinculante, y su ausencia comporta la nulidad radical de la modificación pretendida, como resulta de la legislación y de una antigua y consolidada jurisprudencia ${ }^{4}$. Es cierto que el carácter preceptivo y vinculante de este dictamen no es algo novedoso pues con esta configuración lo estableció la Ley de Zonas Verdes de 2 de diciembre de 1963, y así ha venido figurando tanto en las sucesivas leyes urbanísticas estatales como ahora en la mayoría de las leyes autonómicas sobre la materia, que generalmente remiten al dictamen de su propio Órgano consultivo. Ahora bien, aunque el carácter vinculante de tal dictamen no constituya en sí mismo una novedad, sí es destacable que ahora quede extendido con ese mismo carácter, en el ámbito andaluz, a una serie tan notablemente amplia de supuestos, quedando así invertida la regla natural de que los informes vinculantes han de ser excepcionales, principio que creemos debe regir del modo más estricto cualquiera que sea el sector o la materia en la que se desenvuelva la actuación administrativa, por razones que aquí no podemos pararnos a considerar. Baste insistir en que, a nuestro juicio, los dictámenes no deben ser vinculantes como regla, sobre todo allí donde quede a favor de la Administración que plantea la consulta siquiera un mínimo margen de discrecionalidad, siquiera una brizna de apreciación basada en criterios no estrictamente jurídicos ${ }^{5}$.

\footnotetext{
${ }^{4}$ La Ley de Zonas Verdes sancionaba con la nulidad de pleno derecho los actos de edificación y uso del suelo que constituyeran infracción a los requisitos procedimentales previstos para la modificación de estos espacios, a los que ya hemos hecho referencia en nota anterior. Tal regulación pasó a los textos refundidos de la Ley del Suelo de 1976 (art. 188) y 1992 (art. 255). La LOUA no proclama de manera explícita la nulidad radical de las modificaciones realizadas con infracción del procedimiento especial, aunque ello se deduce implícitamente de su art. 185 al declarar imprescriptible la acción para el ejercicio de la potestad de protección de la legalidad urbanística para los "parques y jardines, espacios libres o infraestructuras o demás reservas para dotaciones"

${ }^{5}$ Unas reflexiones sobre los dictámenes vinculantes puede verse en nuestro estudio "El Consejo Consultivo y el sistema jurídico de Andalucía”, en esta misma Revista, núm. 45, año 2002, pág. 66.
} 
c) Ese incremento de las circunstancias que dan lugar a tan cualificado control conlleva también una mutación en la teleología tradicional de este mecanismo fiscalizador. Desde sus orígenes, la "modificación cualificada" ha estado concebida con una finalidad que pudiéramos denominar "ecológica", esto es, la defensa de las "manchas verdes" y de los "terrenos preparados para juegos y ejercicios físicos al aire libre" (Reglamento de Obras, Servicios y Bienes municipales de $1924^{6}$ ). Como es lógico, defensa también y paralelamente frente a la especulación ${ }^{7}$, o sea, frente -en palabras de la propia Ley de Zonas Verdes de 1963- al "constante acoso que estos espacios libres sufren de los intereses contrapuestos que tienden a incrementar los volúmenes de edificación".

Hay que notar que esta estrecha vinculación del mecanismo de la "modificación cualificada" del planeamiento con la defensa de "lo verde" ha sido la que ha venido proporcionando a los órganos consultivos y a la propia Administración de tutela decisora de estos procedimientos el argumento de fuerza para poder sentar con entereza una doctrina contundente frente a los ataques especulativos del sector privado y frente a esa inercia generalizada de los propios Ayuntamientos que trata de encontrar en la desaparición de estos espacios -o en su centrifugación hacia las zonas urbanas más periféricas y menos "suculentas"- el modo de resolver los problemas más variados que la ciudad plantea.

Esta actitud defensora, concentrada en los espacios verdes, se aprecia palpablemente en la doctrina del Consejo Consultivo de Andalucía que, por una

\footnotetext{
${ }^{6}$ Este histórico Reglamento, de 14 de julio de 1924, estableció un verdadero estándar en defecto de lo que dispusiesen las Ordenanzas municipales, a las que se remitía, consistente en un "mínimo de cuatro metros cuadrados por habitante, siempre que la superficie que resulte no sea inferior al 10 por 100 del área total, a parques y jardines y terrenos preparados para juegos y ejercicios físicos al aire libre..." Es de interés resaltar, por una parte, que el estándar viene referido al conjunto de las zonas verdes y de ocio; y, por otra parte, que el propio precepto mandaba a repartir estos espacios por el territorio "a fin de evitar que los núcleos urbanizados tengan excesiva densidad de población", lo que supone la acogida del principio de que el valor de estos espacios no es sólo cuantitativo, sino cualitativo, un principio presente en los doctrina del Tribunal Supremo y de los Órganos consultivos en esta materia.

${ }^{7}$ Ciertamente, la lucha contra la especulación constituye la razón originaria de la protección especial a las zonas verdes a la vez que la defensa del medio ambiente, definido entonces (en el Preámbulo de la llamada Ley de Zonas Verdes) como los espacios "para la normal expansión de la vida humana fuera del hogar no sólo por imperativos higiénicos y sanitarios, sino también de convivencia social". A esta primaria función de las zonas verdes se han unido otras muy relevantes de corte puramente urbanístico, tales como su papel estructurante del tejido urbano y el de elemento útil para hacer posible la equidistribución de beneficios y cargas.
} 
parte, desde siempre ha afirmado que su misión se centra en proteger las zonas verdes con exclusión de otros problemas urbanísticos concomitantes; y, por otro lado, siempre ha apoyado sus decisiones -desde un dictamen 57/1995, y a través de un Fundamento jurídico "de estilo" que se repite en otros muchos posteriores- en el argumento de peso definitivo: la propia Constitución. Así, se proclama que "la protección de las zonas verdes encuentra amparo en las previsiones constitucionales, en el artículo 45, en cuanto reconoce el derecho a disfrutar de un medio ambiente adecuado...". Argumento poderoso que hace difícilmente rebatible cualquier dictamen o decisión inspirados en esa idea "pro natura" 8

Pues bien, no cabe duda de que la ratio essendi de este procedimiento especial, vinculado tradicionalmente a las zonas verdes y espacios libres, ha cambiado por obra de la LOUA en lo que concierne a la protección de las "dotaciones o equipamientos". Las razones que puedan fundamentar la protección de estos nuevos elementos añadidos a la vieja fórmula, podrán ser acaso iguales de estimables que las esgrimidas para proteger las zonas verdes, pero no las mismas; como tampoco podrán ser iguales los argumentos a utilizar para la tutela de estas dependencias o instalaciones "no verdes".

Lo que sí parece claro es que el criterio a manejar por el Órgano consultivo a la hora de dictaminar sobre la procedencia o no de alterar una dotación o un equipamiento no podrá gozar de un armazón argumentativo tan robusto como el que ha servido para defender las zonas verdes. Será sin duda más débil, sencillamente porque será muy difícil resolver desde criterios jurídicos -los únicos de posible manejo por el órgano consultivo- cuestiones donde priman determinaciones esencialmente técnicas o de oportunidad que son -y deben ser en todo caso- de la competencia de la Administración activa. Es evidente que si un órgano llamado a emitir un dictamen de carácter vinculante tiene limitada su cognición a la perspectiva puramente legal del problema -reducida prácticamente al examen de aspectos de forma o procedimiento- siempre será incompleta su aprehensión de la realidad o su posibilidad de emitir

\footnotetext{
${ }^{8}$ Resulta decisiva al respecto la STC 119/2001 que vincula el medio ambiente urbano con la protección de los derechos fundamentales a la vida, la salud, la intimidad y la inviolabilidad del domicilio". Obviamente, parte esencial de ese medio ambiente urbano son las zonas verdes, consideradas por el dictamen citado en el texto como "enclaves fundamentales ya que contribuyen a conseguir el uso racional del suelo, impidiendo la masificación, favorecen un adecuado desarrollo de la vida ciudadana, facilitando un más cercano contacto con la naturaleza y ofreciendo la posibilidad de contar con áreas de esparcimiento... y favorecen la corrección de los factores contaminantes que invaden las ciudades".
} 
un juicio integral sobre el asunto, con la consiguiente merma de sustancia en la decisión y con el consiguiente riesgo que ello comporta en todo caso, tanto si su dictamen es favorable -pues en tales condiciones podría legitimar o respaldar, aun sin quererlo, una operación que aunque "legal" pudiera ser contraria al interés público e incluso esconder espúreas finalidades- como si es desfavorable. Si este riesgo ya existe en el caso de los dictámenes que tienen por objeto las zonas verdes estrictamente tales, el riesgo se magnifica en todos los demás supuestos en los que la discrecionalidad técnica de la Administración planificadora tiene un campo propio y amplio de ejercicio, y este mismo campo esta cerrado, por mandato de la Ley, a la fiscalización del órgano consultivo, constreñido así a realizar su función de control a través de un dictamen fundado sólo y exclusivamente en Derecho.

\section{DEPURACIÓN DE LOS CONCEPTOS O DEPENDENCIAS OBJE- TO DE LA "MODIFICACIÓN CUALIFICADA"}

\section{A. ZONAS VERDES Y ESPACIOS LIBRES.}

Es oportuno esclarecer en primer lugar este par de conceptos ya que, como queda indicado, sobre ellos se ha asentado tradicionalmente esta llamada "modificación cualificada" del planeamiento que exige la intervención de los altos órganos consultivos.

Dos afirmaciones al respecto pueden hacerse en pro de la brevedad y la claridad de algo proverbialmente confuso tanto en la legislación como en la doctrina y el lenguaje al uso. Primera, en su origen los espacios a proteger vienen referidos a una sola realidad física: los caracterizados por una vegetación permanente; son, pues, las "manchas verdes", así se trate de parques o jardines. Segunda, ante la confusión terminológica reinante en la propia legislación (ya visible en la Ley del Suelo de 1956 e incluso en la de Zonas Verdes de 1963), la perspectiva más adecuada es la de considerar el "espacio libre" de titularidad pública como un género y las zonas verdes como una especie de aquéllos. Se trata, pues, de dos conceptos distintos, aunque subsumido uno en el otro, teniendo en común la característica de su inedificabilidad con el fin de destinarlos a usos colectivos y al ocio ciudadano. Dicho de otro modo, hay un concepto amplio de "espacio libre" donde se incardina la categoría de las zonas verdes; y otro concepto estricto que hace referencia a espacios diversos pero que no son verdes. Por tanto, junto a las zonas verdes o parques urbanos públicos, se integran en los "espacios libres" las áreas públicas dedicadas al ocio cultural y recreativo (o "zonas deportivas de recreo y expansión”) en los 
que quedan comprendidos ejemplos tales como los paseos, incluidos los paseos marítimos ${ }^{9}$, zonas o parques deportivos, ferias, parques zoológicos o de atracciones, y otras instalaciones análogas como auditorios, acuarium, etc.

Ahora bien, aunque ambas categorías pertenezcan al mismo género -espacios libres en sentido amplio- no son (o no debieran ser) libremente intercambiables entre sí puesto que sirven a finalidades diferentes; en todo caso, si se pretende la conversión de algún elemento de una categoría en otra habrá que pasar por los trámites de la modificación cualificada ${ }^{10}$. Ello no es óbice para que ambas categorías constituyan lo que el artículo 25.1.c. del Reglamento de Planeamiento de 1978 denomina como "sistema general de espacios libres", diferenciable de los otros dos sistemas también "generales": comunicaciones y equipamiento comunitario. En suma, la pertenencia a un mismo sistema no debe suponer la intercambiabilidad de sus elementos con ausencia de los debidos controles y garantías.

Esta distinción entre "sistemas", a la que acabamos de referirnos, permite resolver como no pertenecientes al concepto de espacio libre algunos supuestos presuntamente "dudosos" que son objeto frecuente de controversias en sede judicial; así, no pueden considerarse incluidos en dicho concepto los terrenos calificados como suelo no urbanizable ${ }^{11}$; los espacios francos inedificables que han de existir entre edificaciones o entre éstas y las vías públicas en aplicación de los coeficientes de edificabilidad (es decir, que no todo terreno inedificable es un espacio libre); los viales de cualquier clase y sus zonas de protección, aunque éstas sean verdes; así como todo el sistema general de comunicaciones; los aparcamientos, sin perjuicio de que excepcionalmente puedan ubicarse aparcamientos en el seno de zonas verdes -sin que computen como tales zonas verdes- o en su subsuelo; el equipamiento comunitario (servicios culturales, docentes, sanitarios, asistenciales, religiosos, cementerios...).

${ }^{9}$ STS. 19-9-1997, Ar. 6598; STSJ Galicia 27-6-2002, Ar. 866.

${ }^{10}$ En este sentido, SSTS 11-11-1985, Ar. 5549 y 29-12-1986, Ar. 8123.

${ }^{11}$ No obstante, señala GARCİA MANZANO, P., que si un Plan implanta un sistema de zonas verdes en suelo no urbanizable (lo que es posible, puesto que los sistemas generales son independientes de la clasificación del suelo) su modificación tendría que sujetarse al procedimiento especial; "La subordinación del régimen del suelo al 'interés general' establecido en el artículo 128 CE: el supuesto de las zonas verdes", en Estudios sobre la Constitución española. Homenaje al profesor García de Enterría, Vol. V, Edit. Cívitas, Madrid, 1991, pág. 3859. 
Tampoco cabe incluir en dicho concepto los parques, jardines y zonas deportivas privadas, máxime a partir de lo que dispuso el artículo 29.1.d) del Reglamento de Planeamiento y especialmente el artículo 72.2.d) del TR. de 1992, aunque alguna jurisprudencia anterior a este último texto entendiese con alguna parte de razón -y un cierto apoyo en la ambigüedad que ofrecía al respecto el TR. de 1976- que tales terrenos también cumplen una función ecológica al igual que las zonas verdes afectas al demanio y uso público, por lo que podrían formar parte del cómputo a efecto de dar cumplimiento al estándar legal. Pero es evidente que esta tesis se desvanece si la posible alteración de esos terrenos no está sujeta al régimen especial de protección de las zonas verdes públicas ${ }^{12}$, como así ocurre, por excepción, en la legislación urbanística de Cantabria.

Una última precisión. Los espacios libres y, por tanto, las zonas verdes, para tener la condición de tales han de estar así previstos por el Plan. Su condición deriva, pues, de su afectación formal a tales destinos; o dicho en otros términos: no hay espacios libres de hecho o por "predestinación natural". Por ello, los no incluidos por el Plan quedan excluidos del cómputo para alcanzar el estándar legal y de las garantías procedimentales previstas para su modificación.

\section{B. DOTACIONES Y EQUIPAMIENTOS.}

Más complicado resulta desentrañar qué elementos deben entenderse comprendidos en tales conceptos. La LOUA es particularmente imprecisa en este punto y plantea graves dificultades para determinar la extensión del precepto clave que estamos considerando. En efecto, debe notarse que el artículo 36.2.c) 2⿺ $2^{\underline{a}}$, que transcribimos al principio, de entrada ya plantea problemas de orden lingüístico al hablar de "dotaciones o equipamientos", disyuntiva que, gramaticalmente, conduce a la conclusión de que el precepto los considera como sinónimos ya que si hubiese pretendido referirse a dos categorías distintas hubiese utilizado la copulativa "y", y no la disyuntiva "o". Mas la verdad es que no puede haber sinonimia o equivalencia, sencillamente porque se trata de realidades distintas, como resulta de otros pasajes de la Ley.

\footnotetext{
${ }^{12}$ La STSJ de Valladolid 27-3-2002, Ar. 166778, conjugando los preceptos señalados, expresa la solución en términos espacialmente claros: "El procedimiento especial únicamente es exigible cuando la modificación del Plan afecta a parques y jardines públicos"
} 
Por ello resulta necesario desechar toda hermenéutica de carácter literalista, máxime tratándose de una norma como la LOUA, tan abigarrada en lo literario. Baste señalar al respecto el artículo 3.2.b), que hace la interpretación "auténtica" de lo que debe entenderse por suelo dotacional y que viene a desmentir esa presunta equivalencia entre "dotaciones y equipamientos" que podría deducirse del precepto antes transcrito. Así, define el suelo dotacional como

"el que debe servir de soporte a los servicios públicos y usos colectivos; es decir, las infraestructuras, parques, jardines, espacios públicos, dotaciones y equipamientos públicos, cualquiera que sea su uso".

Se trata, como puede apreciarse, de un concepto amplísimo de "dotaciones" que incluye prácticamente todo espacio o instalación pública, cuya aplicación al pie de la letra haría de cualquier alteración del planeamiento, de la alteración de las redes de cualquier infraestructura, una "modificación cualificada" a efectos del preceptivo dictamen del Consejo Consultivo.

En otro precepto, de no menor trascendencia que el anterior, la LOUA sigue sin precisar un concepto de "dotación" operativo en términos jurídicos. Así, el artículo 17.1.2 $2^{\mathrm{a}}$, referido a los estándares o reservas para "dotaciones" enumera una serie de ellas a título de ejemplo, lo que frustra el valor definitorio del precepto. En efecto, éste habla de dotaciones

"tales como parques y jardines, centros docentes, sanitarios o asistenciales, equipamiento deportivo, comercial, cultural o social y aparcamientos..."

A la vista de esta especie de galimatías se impone la necesidad de realizar un deslinde de esas "dotaciones o equipamientos", a los que se refiere el art. 36.2.c) 2 $2^{a}$, que ofrezca una cierta seguridad, dada la importancia de tener una idea muy clara de qué alteración del planeamiento debe pasar o no por el procedimiento de una "modificación cualificada". Pues bien, al igual que antes se dijo sobre que el "espacio libre" constituye un género que engloba dos especies -una de ellas la de "zonas verdes"-, aquí podemos decir que la "dotación" es el supraconcepto que engloba dos especies: los "equipamientos" por un lado (administrativos, docentes, sanitarios, asistenciales, culturales, cementerios...), o sea, dotaciones que en sí mismas constituyen un servicio; y por otro lado las "infraestructuras" que operan como soporte material de servicios públicos, tales como la red viaria, redes de distribución de energía, agua, alcantarillado, gas, alumbrado público, telefonía y, desde luego, los aparcamientos. Y también se incluirían en la categoría de "infraestructuras" los propios espa- 
cios libres, si bien con ese carácter de subcategoría separada y autónoma que han ostentando desde siempre, como ya vimos en el epígrafe anterior.

Como puede deducirse de lo expuesto, el panorama es bien complejo. No se puede dar a la expresión "dotaciones o equipamientos" del referido artículo 36.2.c) 2 $2^{\underline{a}}$ una extensión desmesurada que haga intervenir al Consejo Consultivo en todo ese mundo de incidencias, ni tampoco se puede dar al precepto una interpretación restrictiva que le haga decir menos de lo que la LOUA ha querido decir, se comparta o no la solución legal.

Pues bien, en una línea interpretativa que nos atrevemos a calificar de razonable y, desde luego, de manejable desde criterios jurídicos, la conclusión que parece más acertada es la de incluir en el concepto de "dotación" -a efecto, repetimos, del precepto referido a la modificación cualificada- la totalidad de los equipamientos; y en cuanto a las infraestructuras sólo las que tienen señaladas por la propia LOUA estándares mínimos a cumplir, es decir, los "espacios libres" en su sentido amplio -y propio- que antes definimos; y los aparcamientos.

\section{EN TORNO A LOS ESTÁNDARES ESTABLECIDOS POR LA LOUA}

Dejando al margen las previsiones de la LOUA sobre los estándares relativos a la densidad de la edificación y al número de viviendas por hectárea, aspectos de los que aquí no hemos de ocuparnos, los parámetros que sí hemos de tener en cuenta son los que la propia LOUA refiere, por un lado, a las "dotaciones" en general (con la extensión que ya hemos dado a este concepto en el epígrafe anterior) y, por otra parte a los "parques y jardines". Por consiguiente, hay que considerar dos estándares superpuestos: el general referido al conjunto de las dotaciones y el específico para los "parques y jardines", es decir, las zonas verdes stricto sensu.

\section{A. UN ÚNICO ESTÁNDAR PARA TODO EL TERRITORIO (EXCLUIDO} EL SUELO NO URBANIZABLE).

Para valorar la solución de la LOUA en este punto, la referencia comparativa no puede ser otra que la establecida en su día por el art. 72.2.d) del TR de 1992, según el cual:

"Los Planes-Generales y las Normas Subsidiarias de Planeamiento- deberán incluir los sistemas generales de... espacios libres destinados a parques pú- 
blicos y zonas verdes en proporción no inferior a cinco metros cuadrados por habitante"

Hay que observar que este estándar, referido a toda la ciudad con independencia de la clasificación del suelo -excluido el suelo no urbanizable- recaía exclusivamente sobre las "manchas verdes". Por tanto, éstas serían las únicas superficies a computar para cumplir la ratio de $5 \mathrm{~m}^{2} / \mathrm{hab}$.

Las Leyes urbanísticas de algunas Comunidades Autónomas han incorporado esta misma solución o con algún pequeño matiz diferencial (Asturias, La Rioja, Navarra, Comunidad Valenciana); otras no establecen ningún estándar de zona verde con este carácter general (Canarias, Cantabria, Castilla-León, Castilla-La Mancha, Cataluña, Extremadura, Madrid, Murcia). Y otras establecen el estándar pero no exclusivamente para las zonas verdes, sino para el conjunto de espacios libres públicos; así ocurre en el caso de Aragón y Galicia y también en el de Andalucía, aunque con una ratio $\mathrm{m}^{2} / \mathrm{habi}$ tante distinta en cada caso.

En efecto, el artículo 10.1.A.c.1 de la LOUA prevé que entre las determinaciones estructurales del Plan General quede respetado un estándar mínimo "de entre 5 y 10 metros cuadrados por habitante", a determinar reglamentariamente según las características del municipio, para "parques, jardines y espacios libres públicos”. Salta a la vista la diferencia de este régimen respecto a su precedente de la Ley estatal en lo que atañe a la protección de las zonas verdes, dado que la LOUA refiere el estándar no sólo a éstas sino al conjunto de los espacios libres. Por tanto, aunque el porcentaje por habitante puede llegar a ser de hasta 10 metros cuadrados, sin embargo los parques y jardines sólo virtualmente quedan asegurados, pues, en hipótesis, podría ser perfectamente cumplido el estándar aunque para ello se computasen mayormente áreas de recreo (paseos marítimos, zonas de ocio, etc.) y no parques y jardines; o sea, los elementos a computar resultan así intercambiables pues la LOUA no reserva un porcentaje específico para zona verde. Sería conveniente que el desarrollo reglamentario que anuncia el propio precepto estableciera un mínimo de seguridad para los parques y jardines.

En todo caso, la protección de esta reserva juega fundamentalmente en el proceso de su implantación y en el de la revisión del planeamiento ya que al venir esta masa de terreno verde normalmente constituida por espacios asentados en la estructura general del territorio, su alteración tendría que articularse a través de una revisión del Plan, por constituir una mutación sustancial de la ordenación estructural del PGOU (art. 37.1), lo cual implica su exclu- 
sión del procedimiento de modificación y, por tanto, la no intervención del Consejo Consultivo. De todos modos este estándar general jugará siempre su papel como elemento de control complementario en los procedimientos de modificación "cualificada”, ya que es condición básica -entre otras- para que pueda autorizarse cualquier alteración de zona verde es que el estándar general se mantenga.

\section{B. LOS DISTINTOS ESTÁNDARES “DE SECTOR”}

Son los referidos a las porciones de suelo urbanizable a ejecutar normalmente mediante Planes Parciales; y a los terrenos que han de ser ordenados mediante Planes Especiales de Reforma Interior; y también al suelo urbano no consolidado, por expresa determinación de la LOUA, que sigue en este punto la misma solución que la legislación de Galicia, Madrid, Navarra y Castilla-León ${ }^{13}$. No lo han dispuesto así otras Comunidades Autónomas.

La Ley del Suelo estatal, TR de 1992 (art. 83.2.c), estableció un estándar "de sector" para el conjunto de los espacios libres de dominio y uso público, es decir, para la categoría genérica que engloba las zonas verdes y el resto de los espacios libres. Por tanto éstos eran susceptibles de intercambio entre sí ${ }^{14}$. Los parámetros a respetar eran: 18 metros cuadrados por vivienda o por cada 100 $\mathrm{m}^{2}$ de edificación residencial (si no se hubiera fijado expresamente el núme-

${ }^{13}$ La LOUA no establece diferencia de tratamiento al suelo urbano no consolidado. Sí lo hace, por ejemplo la legislación de Castilla-León, al gravar menos éste (15 por 100 de la superficie construible de uso predominante) que el suelo urbanizable (20 por 100). Pero el art. 17.2. de la LOUA prevé la posibilidad de eximir parcialmente de este régimen concretos sectores de suelo urbano no consolidado "cuando las dimensiones de éstos o su grado de ocupación por la edificación hagan inviable dicho cumplimiento o éste resulte incompatible con una ordenación coherente"; y también permite tal exención cuando en sectores de dicho suelo "se hayan llevado irregularmente a cabo, total o parcialmente, actuaciones de urbanización y edificación que el Plan General de Ordenación Urbanística declare expresamente compatibles con el modelo territorial que adopte”, supuesto éste que extiende al suelo urbanizable.

\footnotetext{
${ }^{14}$ No obstante, el art. 49.1 del Reglamento de Planeamiento, RD 23 junio 1978, señala que las reservas de terreno de dominio y uso público que el Plan Parcial debe establecer para jardines, zonas deportivas, de recreo y expansión, se fijarán diferenciando cada uno de estos usos. Y el Anexo del Reglamento (art. 3) al Reglamento de Planeamiento obliga a establecer jardines tanto en suelo residencial como industrial y terciario, lo que supone que esa intercambiabilidad de la que hablamos en el texto no puede ser absoluta. Por otra parte, el apartado 2 de dicho art. 49 hace una llamada a la vertebración racional del territorio: "En la configuración de estas áreas se evitará el fraccionamiento que invalide su finalidad esencial, debiendo justificarse que constituye un sistema coherente".
} 
ro de viviendas a construir); y en todo caso, nunca inferior al 10 por 100 de la superficie total ordenada.

Con independencia de ese estándar específico para espacios libres la Ley obligaba a que los Planes Parciales contuviesen determinaciones relativas a los equipamientos (centros culturales y docentes, templos, centros asistenciales y sanitarios y demás servicios de interés público y social), pero sólo para los centros culturales y docentes establecía un estándar propiamente dicho, al cifrar para éstos una proporción mínima de $10 \mathrm{~m}^{2} /$ vivienda o por cada $100 \mathrm{~m}^{2}$ de edificación residencial si no se hubieran determinado expresamente el número de viviendas que se pudieran construir (art. 83.2, letra d). Del mismo modo resolvía lo concerniente a las infraestructuras (red de comunicaciones, galerías y redes de abastecimiento de agua, alcantarillado, energía eléctrica, otros servicios previstos por el Plan y aparcamientos), fijando sólo para éstos últimos un estándar mínimo de una plaza de aparcamiento por cada $100 \mathrm{~m}^{2}$ de edificación (art. 83.2, letra f). Por consiguiente, había que distinguir tres bloques de dotaciones: equipamientos, infraestructuras y sistema de espacios libres, en cada uno de los cuales se establecía un estándar específico para alguno o todos de sus elementos; así, respectivamente: centros culturales y docentes, aparcamientos, y la totalidad de espacios libres. En suma, estándares independientes cuya suma constituiría una buena parte de la reserva total destinada a dotaciones públicas del sector de que se trate.

Sobre esta referencia de partida, la legislación urbanística autonómica ha creado un panorama de soluciones muy diversas. Así, el estándar viene referido exclusivamente a las zonas verdes (Castilla-La Mancha); en otros casos comprende el conjunto de espacios libres (Cataluña, Galicia, Navarra); y en otros se le suman a estos últimos los equipamientos, con lo cual disminuye, lógicamente, la calidad de la reserva (Castilla-León).

Desde distintos ángulos podríamos seguir detectando otras diferencias de ese derecho autonómico comparado, tales como los distintos niveles de porcentajes constitutivos del estándar o sus respectivos modos de aplicación. Pero más útil nos parece resaltar las características propias de este régimen en Andalucía, a la vista de lo dispuesto en el art. 17.1.2 $2^{\underline{a}}$ de la LOUA, que transcribimos a continuación:

"Reservas para dotaciones tales como parques y jardines, centros docentes, sanitarios o asistenciales, equipamiento deportivo, comercial, cultural o social y aparcamientos... deben cumplir como mínimo los siguientes estándares" 
a) En suelo con uso característico residencial, entre 30 y 55 metros cuadrados de suelo por cada 100 metros cuadrados de techo edificable con uso residencial, de los que entre 18 y 21 metros cuadrados de suelo, y nunca menos del diez por ciento de la superficie del sector, deberán destinarse a parques y jardines, y además, entre 0,5 y 1 plaza de aparcamiento público por cada 100 metros cuadrados de techo edificable.

b) En suelo con uso característico industrial o terciario, entre el catorce y el veinte por ciento de la superficie del sector, debiendo destinarse como mínimo el diez por ciento a parques y jardines; además, entre 0,5 y 1 plaza de aparcamiento público por cada 100 metros cuadrados de techo edificable.

c) En suelo con uso característico turístico, entre el veinticinco y el treinta por ciento de la superficie del sector, debiendo destinarse como minimo el veinte por ciento del sector a parques y jardines, y además, entre 1 y 1,5 plazas de aparcamiento público por cada 100 metros cuadrados de techo edificable.

Del precepto antes transcrito conviene retener las siguientes notas:

a) Establece estándares distintos para cada tipo de uso (residencial, industrial o terciario y turístico) al igual que ocurre en otras Comunidades $\mathrm{Au}$ tónomas (Castilla-La Mancha, Cataluña, Extremadura, Galicia, Navarra).

b) Incluye dotaciones diversas que componen un círculo notablemente mayor que el de "espacio libre" y, por supuesto, que el de zona verde. Como ya advertimos más arriba el precepto que comentamos no ha cuidado de precisar las dotaciones concretas a las que se está refiriendo, enumerando, sólo de modo ejemplificativo, algunos equipamientos y algunas infraestructuras. Como también antes afirmamos, los ejemplos que cita relativos a infraestructuras (parques y jardines y aparcamientos) prácticamente agotan los supuestos de tal clase cuya alteración ha de ser sometida al procedimiento de "modificación cualificada”, aunque el precepto se olvida de mencionar los demás espacios libres (zonas de recreo, ocio y expansión), que junto a los sí mencionados (parques y jardines) componen el sistema de espacios libres, integrados a su vez en el supraconcepto "infraestructuras". Por otra parte, hay que tener en cuenta que los equipamientos a tener en cuenta son más de los que menciona el precepto en cuestión, dado que han de entenderse incluidos en él todos los equipamientos.

c) Se establece un doble estándar para cada uno de los tres tipos de uso del suelo que el precepto contempla: uno general para el conjunto de las do- 
taciones, y otro paralelo o de seguridad para las zonas verdes, o sea, "parques y jardines". A diferencia de lo que hemos afirmado en el epígrafe anterior respecto al estándar general para toda la ciudad, la LOUA es aquí notablemente progresiva, precisamente por configurar verdaderos estándares específicos y exclusivos para parques y jardines, y en un estimable nivel porcentual. Ello impide que estas zonas verdes puedan ser confundidas con los demás espacios libres y, por supuesto, con el resto de las dotaciones, lo que implica que no puedan ser sustituidas o suplantadas por éstos.

En suma, las zonas verdes no son convertibles en otros espacios libres "no verdes" ni en otros equipamientos o dotaciones, así que quedan "blindadas" por obra de la LOUA frente a otra de sus tradicionales amenazas: la de su conversión en otros destinos igualmente públicos y, en la mayoría de los casos, análogamente beneficiosos para el interés general; argumento éste muchas veces utilizado para "ablandar" la rigidez de la defensa de los parques y jardines. Pero estas "buenas razones" que han podido justificar la conversión de una zona verde en una infraestructura distinta o en un equipamiento -¿quién no sería sensible ante la demanda de convertir una parcela de zona verde poco atractiva en un centro escolar que fuese necesario?- resultan a la postre indeseables ya que el beneficio que puede derivar de esa conversión es a costa de algo tan difícil o imposible de compensar como es la desaparición de un parque o un jardín; una pérdida que en la práctica será normalmente irreversible, sencillamente porque las zonas verdes, aunque reputadas en abstracto como de trascendencia vital, son al fin y al cabo espacios prescindibles, a diferencia de lo que ocurre con otras dotaciones, a las que siempre habrá de buscárseles un lugar adecuado para su implantación, sea o no a costa de terrenos verdes.

d) La bondad sustancial de la norma que comentamos, al reservar mínimos de zona verde de $18 \mathrm{~m}^{2} / 100 \mathrm{~m}^{2}$ de techo edificable (uso residencial), 10 por 100 de la superficie (uso industrial o terciario) y 20 por 100 de la superficie (uso turístico), no excluye que deba ser censurada por su imprecisión, dada la importancia del tema de que trata.

En efecto, hay que insistir en su criticable forma de enumerar las dotaciones públicas que han de reservarse, siendo bastante impropio, a nuestro juicio, que figuren a título de ejemplo y sin orden lógico alguno. En segundo lugar, y tomando como ejemplo el supuesto de la letra “a)", referido al suelo residencial -extiéndase la crítica, mutatis muntandi, a los demás supuestos- el precepto abre un abanico de discrecionalidad que puede juzgarse excesivamente amplio -de 30 a $55 \mathrm{~m}^{2}$ de superficie/100 $\mathrm{m}^{2}$ de techo edificable- ya 
que puede dar lugar a notables diferencias entre sectores en cuanto a su nivel de dotaciones $\left( \pm 25 \mathrm{~m}^{2}\right)$. Además, como la reserva prevista para parques y jardines, dentro de ese montante global para dotaciones, se mueve en unos márgenes mucho menos elásticos (entre 18 y 21 metros), puede resultar en algún caso que el quantum de terrenos a destinar a dotaciones distintas de zona verde pueda ser muy exiguo; así, en el peor de los casos pueden restar sólo $9 \mathrm{~m}^{2}$ $\left(30 \mathrm{~m}^{2}-21 \mathrm{~m}^{2}\right.$ zona verde), y en el mejor $37 \mathrm{~m}^{2}\left(55 \mathrm{~m}^{2}-18 \mathrm{~m}^{2}\right.$ zona verde), es decir, una banda de oscilación entre uno y otro de $28 \mathrm{~m}^{2}\left(37 \mathrm{~m}^{2}-9 \mathrm{~m}^{2}\right)$, lo cual parece excesivo.

Pero sobre todo, la desafortunada redacción de la norma genera una duda absurda en lo que atañe a la reserva para aparcamientos. Debe notarse que la regla $2^{\underline{a}}$ del art. 17.1 que estamos comentando incluye entre las "reservas para dotaciones", a título de ejemplo, también los aparcamientos. Además de ello debe observarse que en las respectivas letras a), b) y c) de dicha regla, tras establecer los estándares referidos a "parques y jardines" (cuyas superficies se incluyen, sin ninguna duda, dentro de los montantes globales destinados a dotaciones), se dice que "además"-sic-deben destinarse plazas de aparcamiento en número respectivamente distinto, según cada tipo de uso del suelo.

Pues bien, a partir de estas premisas pueden caber dos interpretaciones: primera, que estos estándares específicos para aparcamientos estén incluidos dentro del número global de $\mathrm{m}^{2}$ reservados para dotaciones, al igual que ocurre con los parques y jardines, o sea, que la expresión "además" que utiliza la norma esté sintácticamente unida, en conexión continuativa, con lo previsto para las zonas verdes. Segunda, que los estándares para aparcamientos constituyan reservas distintas e independientes de los globales previstos para el conjunto de dotaciones de cada tipología de uso; es decir, que la expresión "además" lo es respecto de cada reserva global, resultando de ello que la superficie a destinar a los aparcamientos representan una dotación adicional a la referida a las dotaciones genéricamente consideradas, enunciadas ad exemplum al comienzo de la regla referida. Podría oponerse a esta última interpretación el hecho de que los aparcamientos ya figuran en el encabezado de la regla como uno de esos ejemplos, lo que conduciría a estimarlos integrados en el conjunto de las dotaciones. Pero parece más correcto considerar que se trata de una reserva propia y autónoma que se añade a la reserva genérica para las dotaciones, interpretación ésta que resulta coherente con las previsiones sobre reservas para aparcamientos que se contiene en el Reglamento de Planeamiento de 1978. 


\section{SOBRE EL CARÁCTER NO INTERCAMBIABLE DE ESTOS ES- PACIOS.}

La doctrina del Consejo Consultivo sobre la tutela de los parques y jardines y demás espacios libres, cimentada en un ya lejano dictamen 14/1994 de 30 de septiembre, puede calificarse en términos generales como muy rigurosa e incluso severa en cuanto a la exigencia del cumplimiento de las formalidades que deben seguirse en la tramitación de estos procedimientos. Cabe recordar aquí sus pronunciamientos -siguiendo la huella de la doctrina del Tribunal Supremo y del Consejo de Estado- sobre la exigencia del procedimiento especial con independencia de que la superficie objeto de la alteración aumente o disminuya; o en los casos de permuta; o aunque se trate de modificaciones reducidas o insignificantes ${ }^{15}$. Es obligado destacar la importancia que dicho Órgano concede a la Memoria que ha de figurar en los respectivos expedientes, exigiendo no sólo pulcritud en su motivación, en la acreditación de que la modificación obedece a razones de interés general y en la justificación de que los estándares legales se mantienen tras la alteración de estos espacios ("pues el Consejo no puede presumir que tales estándares se estén respetando, por pequeña que sea la parcela"; Dictamen 8/1995), sino que dicha Memoria conste en el expediente desde su inicio, a efecto de que la participación ciudadana a través de la información pública tenga verdadero valor y sentido pues "resultaría estéril si no se pudiera obtener un concreto conocimiento de los motivos que han alumbrado las decisiones adoptadas" (Dictamen 14/1994).

${ }^{15}$ En contra de esta doctrina, ciertamente rígida aunque a nuestro juicio adecuada y consecuente con la naturaleza "sensible del tema, tan preñado siempre de intereses, podemos registrar soluciones distintas. Así, en la legislación urbanística de La Rioja que no considera modificación los reajustes del Plan General siempre que no se disminuyan las superficies de zonas verdes o espacios libres de dominio y uso públicos. También en la legislación de la Comunidad de Madrid que, por una parte, no considera la disminución de la zona verde como modificación del Plan sino como revisión -con lo cual queda excluido el control por parte del Consejo de Estado-, y por otra, las alteraciones que sí se califican como modificaciones (aumentos y permutas) tampoco están sujetas a procedimiento especial, dado que la Ley de Madrid no lo contempla. A la vista de este régimen la STSJ de Madrid de 27-11-2002, Ar. 55216, dice que aunque la modificación del planeamiento produzca una alteración de la calificación urbanística correspondiente a las zonas verdes y espacios libres previstos en el Plan, si la alteración no produce disminución de las mismas no requerirá informe previo del Consejo de Estado.

Un discutible pronunciamiento se contiene en la Sentencia del TSJ de Cataluña de 30-11-2001. Suprimida una parcela de zona verde que pasó a integrarse en el suelo no urbanizable, la Sentencia no ve anomalía alguna en ello puesto que la parcela "vuelve a su condición original de suelo no apto para urbanizar". 
En cambio, en cuanto a los aspectos sustanciales de las modificaciones mismas, su doctrina puede calificarse como flexible o intermedia pues ni puede reputarse como permisiva antes las modificaciones que los Ayuntamientos proponen ni tampoco cabe decir que dicho Órgano esté afincado en una postura cerrada a toda alteración. Más exactamente podría decirse que existen aspectos sobre los que el Consejo Consultivo mantiene posturas muy firmes, mientras que en otros se muestra muy permeable, quizás excesivamente.

En su faceta "severa" cabe recordar, si bien muy sucintamente, sus pronunciamientos sobre la improcedencia de aceptar la supresión de una zona verde cuando el argumento que se esgrime para ello es simplemente que el espacio en cuestión es inútil como zona verde, pues declara el Consejo -en línea con la jurisprudencia del Tribunal Supremo- que no puede presumirse que el planeamiento que así la calificó fue irracional, ni es aceptable que la modificación del planeamiento pueda servir para reparar decisiones irregulares o anómalas. También ha declarado dicho Órgano la improcedencia de admitir necesariamente la modificación por el hecho de que la zona verde que se pretende reubicar en otro lugar lo sea con mayor tamaño, pues "el concepto de zona verde no es simplemente cuantitativo, sino cualitativo, y no debe tenerse sólo en cuenta su extensión superficial sino también el resto de las circunstancias que concurren en cada caso". Estos criterios han llevado al Consejo a proscribir que las zonas verdes se reubiquen junto al suelo no urbanizable, o al lado de una carretera peligrosa, o en terrenos escarpados, o lejos del núcleo de población, o que quede desarticulada impidiéndose que cumplan su función ya que el espacio ha de ser idóneo y útil como objeto de uso y elemento integrador de una trama territorial racionalmente organizada.

Sin embargo, junto a esta línea doctrinal rígida, ciertamente impecable, discurre otra mucho más liviana, sin duda atenta o sensible a necesidades manifestadas por las Corporaciones locales promotoras de las modificaciones sometidas a dictamen, pero que dicho Consejo tendrá que rectificar sobre todo a la vista de la nueva regulación que la LOUA ha ofrecido en esta materia.

El germen de esta postura permisiva a la que nos referimos puede hallarse en una consideración "de estilo", visible en no pocos pronunciamientos del Órgano consultivo, expresiva de que "el control reforzado que se ejerce sobre estos espacios no significa que no puedan ser alterados, pues el interés público no exige la petrificación para siempre de una determinada trama urbana, y puede demandar tanto el mantenimiento de las zonas verdes como su modificación, permuta o incluso supresión, en función de las circunstancias especí- 
ficas de cada caso". En la práctica, esta filosofía se ha venido materializando en dos vertientes distintas que examinamos a continuación:

a) De una parte, se aprecia una postura del Órgano consultivo bastante condescendiente con alteraciones de zonas verdes que se justificaban por su conversión en otros espacios libres y en equipamientos, dando con ello incluso por demostrada la concurrencia de la causa de interés público que ha de exigirse, como premisa mayor, en toda modificación. Desde esta actitud permisiva ha sido reconocida la pertinencia de convertir zonas verdes no sólo en espacios libres (así, en zonas para instalaciones recreativas o deportivas) con los que ciertamente guarda esa cierta "relación familiar" que ha posibilitado tradicionalmente su confusión y por ello su respectiva fungibilidad o intercambiabilidad, sino sobre todo con genuinos equipamientos (así, supresión o permuta de la zona verde para establecer la sede de la policía local, para cementerios, centros de salud, centros escolares, viviendas de protección pública, ampliación de la red de saneamiento, usos sociales, etc.), dotaciones éstas que, en puridad, en ningún caso deben ser implantadas a costa de la zona verde puesto que pertenecen a otro "sistema", esto es, al sistema de equipamientos que tiene su propio régimen y sus propias previsiones.

Esta postura abierta, visible en la doctrina del Consejo Consultivo, podía encontrar algún apoyo en el TR de 1992, pues como ya observamos más arriba, la forma de regular éste el "estándar de sector" hacía viable el intercambio entre zonas verdes y el resto de espacios libres (no, desde luego, el intercambio con los equipamientos). Pero ahora la LOUA ha hecho desaparecer esa permutabilidad: las zonas verdes no pueden ser sustituidas por nada, puesto que recae sobre ellas un estándar específico y singular no compartido por ningún otro espacio distinto del de zona verde.

b) La otra vertiente por donde discurre esa postura del Consejo Consultivo que podemos calificar como permeable a las alteraciones de zonas verdes hay que centrarla en una pregunta que vendría a ser el lógico complemento de las consideraciones que venimos de exponer y de cuya respuesta depende, en definitiva, si se puede sentar la categórica afirmación de que los parques y jardines no pueden ser objeto de transformación en ningún caso en otros espacios o dotaciones que no sean zona verde. La pregunta es muy simple: en el caso de que los estándares de zona verde se encuentren sobradamente cubiertos en un supuesto determinado ¿cabe reducir libremente la zona verde siempre que se mantenga el mínimo legal?

La respuesta a esta importante cuestión aconseja hacer una aclaración previa que no por obvia es menos necesaria. Sabemos que los estándares le- 
gales tienen valor de mínimos de cumplimiento inexcusable por los planes; pero, lógicamente, no existe óbice para que el planeamiento pueda destinar un porcentaje superior, o sea, pueda aumentar el nivel de la dotación. Pues bien, en tal caso se plantean dos cuestiones: primera, si la alteración posterior de la zona verde -en la parte que excede del estándar legal- exige el procedimiento de "modificación cualificada"; segunda, si el nivel de la masa de zona verde constituida por el Plan (superior al mínimo legal) constituye, per se, un nuevo estándar "de hecho" que se sobrepone al estándar legal y lo desplaza.

La primera cuestión es de fácil respuesta: siempre será exigible el procedimiento de "modificación cualificada" 16 , tanto por el hecho de que la Ley no distingue como porque, en cualquier caso, habrá que controlar si efectivamente con la reducción de la zona verde se sigue respetando o no el mínimo legal.

Sobre la segunda y más crucial cuestión existen dos posturas o doctrinas muy distintas que exponemos seguidamente.

a) una doctrina permisiva, actualmente minoritaria, que es la que viene sosteniendo el Consejo Consultivo de Andalucía. Se encuentra claramente expresada en no pocos de sus dictámenes. Basta con transcribir lo que afirma el dictamen 29/1998:

"La reducción del espacio libre puede ser posible, siempre que se respeten los minimos legales. No cabe, por tanto, establecer reglas generales, pudiendo admitirse como perfectamente lícita la reducción o supresión de un espacio libre, aunque no se compense con una superficie de igual extensión con diferente ubicación territorial (siempre que se respeten los estándares), en cuanto medie una justificación cumplida que acredite el carácter prescindible del espacio en relación con los intereses generales".

La postura es bien clara: hay que respetar rigurosamente los mínimos legales; pero a partir de este respeto el resto de la zona verde existente es en principio disponible por lo que puede ser "perfectamente lícita" la reducción o supresión de un espacio.

b) Una postura diametralmente contraria es la que sostienen expresamente algunas leyes autonómicas que ante las alteraciones de las zonas verdes

${ }^{16}$ En este sentido, la STS de 7-6-1989, Ar. 4513 
exigen el mantenimiento de la superficie y que la nueva zona sea de igual calidad y en condiciones topográficas similares (Aragón, Canarias, Cantabria, Galicia, La Rioja, Murcia; con ligeras matizaciones entre sí que no alteran la idea básica). Asimismo, siguen esta doctrina algunas Sentencias de Tribunales Superiores de Justicia y, sobre todo, es doctrina consolidada del Consejo de Estado, patente en dictámenes tales como los de 17 de octubre y 19 de diciembre de 2002 (2292 y 3297, respectivamente:

"A la hora de modificar los instrumentos de planeamiento, la potestad de la Administración no es omnimoda cuando recae sobre zonas verdes. Debe respetar siempre el arquetipo (standard) mínimo legal en cuanto a su superficie... Pero además este Consejo de Estado ha sentado el criterio de que aunque se supere dicho arquetipo (standard), la modificación no puede comportar disminución de las superficies totales destinadas a zonas verdes, salvo existencia acreditada de un interés público prevalente. En otros términos, la superficie de zona verde en un municipio se configura como un minimo sin retorno, a modo de cláusula stand still propia del Derecho comunitario, que debe respetar la Administración. Sólo es dable minorar dicha superficie cuando existe un interés público especialmente prevalente, acreditado y general; no cabe cuando dicho interés es particular o privado, por gran relevancia social que tenga”.

No es difícil adscribirse a esta última doctrina por su superioridad no sólo teórica, sino práctica. En el plano teórico porque no hay razón que impida suscribir una solución que trata de evitar la disminución del nivel de calidad alcanzado de hecho por una ciudad en lo que atañe a sus parques y jardines, máxime si se tiene en cuenta -amén de innumerables razones que tienen que ver con la habitabilidad de las ciudades, con la estética, desahogo de la circulación, etc.- que este nivel está muy por debajo, dicho sea en términos generales, de lo que recomienda la Organización Mundial de la Salud, que cifra el objetivo a alcanzar en $\operatorname{los} 11,5 \mathrm{~m}^{2}$ de zona verde por habitante, al menos para poblaciones de más de un millón de personas. Y desde una perspectiva práctica porque a efecto del control del Órgano consultivo, la referencia cercana de la zona verde "de hecho" como punto de partida inmediato, real y concreto que hay que respetar aporta un dato directo y decisivo a la hora de comprender el alcance de cada operación urbanística modificatoria de la zona verde, dato mucho más próximo y fiable del que puede extraerse de las motivaciones administrativas -contenidas en la Memoria- prestas a demostrar que la alteración pretendida no infringe el estándar mínimo legal, cálculo éste de mucha más difícil apreciación -y, por tanto, de fiscalización- por venir referido casi siempre a un ámbito físico superior al de la propia parcela verde cuya modificación se pretende. 
Con esta doctrina se consuma de modo prácticamente absoluto la regla de la intangibilidad abstracta del quantum de zonas verdes, sin perjuicio de que, eventualmente, éstas puedan ser cambiadas de ubicación. Por tanto, alterabilidad in loco, no in substantia. Una doctrina, en suma, que debiera ser acogida por el Consejo Consultivo de Andalucía.

Es cierto que esta consideración como un "mínimo sin retorno" de los niveles de zona verde alcanzados de hecho puede resultar una regla excesivamente rígida en algún supuesto, de ahí que la propia doctrina del Consejo de Estado no se exprese en términos absolutos dejando una válvula de escape que permita dar salida a algún caso en que concurra un "interés público especialmente prevalente, acreditado y general", aunque ya hemos visto que en alguna legislación autonómica la prohibición de retroceder es absoluta. Y esta última es la solución que nos parece más correcta aunque pudiera ser juzgada, prima facie, como una postura integrista en pro de las zonas verdes que pudiera chocar con la flexibilidad aconsejable en casos excepcionales, pues debe tenerse en cuenta que lo que se exige no es que se mantenga el tamaño de la parcela verde que se pretende modificar sino el nivel ya alcanzado por el conjunto de las zonas verdes, y esto aporta de suyo un factor de flexibilidad que hace innecesaria la previsión de excepciones a la regla del "mínimo sin retorno" como la que hace la propia doctrina del Consejo de Estado.

Lo importante es que la tesis del "mínimo sin retorno" constituya una regla del sistema -incluso aunque no sea absoluta- y no una excepción. Ciertamente, puede confiarse en que una regla así expresada podrá ser aplicada en la inmensa mayoría de los casos dado el valor nuclear que encierra, tanto en el plano legal como en la convicción social, la defensa de los parques y jardines como algo especialmente preciado en cuanto relacionado con la salud y con un ideal de calidad de vida que es visualizable y anhelable por todo sujeto sin excepción, al menos en su dimensión de individuo aislado que se relaciona con el entorno.

Por el contrario, difícilmente podría ser trasladada esa misma regla a los restantes espacios libres pues ello introduciría un factor de rigidez en el diseño de la ciudad que sería insostenible en la mayoría de los casos. En efecto, no podría comprenderse la razón que sustentara el designio de que un paseo no pueda ser remodelado aun perdiendo superficie o que una zona cualquiera de ocio no pueda ser reducida en beneficio de otras atenciones prioritarias. Pero mucho más difícil, por no decir imposible, sería tratar de aplicar esa regla al caso de los equipamientos pues parece claro que la inmutabilidad o la fijeza no puede erigirse en un valor absoluto en este caso. Los equipamientos debe- 
rán estar dimensionados en cada momento en función de lo que demanden las necesidades públicas, y por ello podrán crecer o disminuir, siendo por tanto irrazonable cualquier postura apriorística que postulara el mantenimiento a ultranza de la configuración que hubiesen alcanzado de hecho, sin retorno posible. Aquí se pone de manifiesto la dificultad que ha de representar para el Consejo Consultivo el ejercicio de su función controladora sobre la modificación de estos "equipamientos", para la cual carece de cualquier parámetro jurídico mínimamente seguro, como dijimos al principio. La tarea en estos casos no puede penetrar más allá de la epidermis de los asuntos, circunscrita al control de los meros elementos reglados externos, de pura forma y procedimiento, de la operación de que se trate.

En cualquier caso, aun con sus dificultades de aplicación en la práctica -no, desde luego, en el caso de las zonas verdes- la línea de principio a seguir no puede ser otra que la de instalarse en la tesis del "nivel de hecho sin retorno" y ello incluso en relación con todas las dotaciones, al menos como punto de partida, salvo en el caso de los parques y jardines en que debe ser no sólo regla sino objetivo final a conseguir. Cierto es que la LOUA no explicita directamente una regla de tal calado y de alcance tan general. Ya hemos visto que sí la proclaman y de manera terminante otras leyes autonómicas, si bien sólo en relación con las zonas verdes. Pero esta línea de principio sí puede inducirse de algunas determinaciones de la propia LOUA. Así, esa cláusula stand still a que hace referencia el Consejo de Estado se encuentra realmente presente en el artículo 36.2.a. $2^{a}$ de la LOUA al decir que

"Toda innovación que aumente el aprovechamiento lucrativo de algún terreno, desafecte el suelo de un destino público a parques y jardines, dotaciones o equipamientos, o suprima determinaciones que vinculen terrenos al uso de viviendas de protección oficial u otros regímenes de protección pública, deberá contemplar las medidas compensatorias precisas para mantener la proporción y calidad de las dotaciones previstas respecto al aprovechamiento, sin incrementar éste en detrimento de la proporción ya alcanzada entre unas y otro"

El precepto transcrito viene a ser trasunto de otro contenido en el art. 128.2. de la Ley del Suelo, TR 1992, según el cual "cuando la modificación tendiera a incrementar el volumen edificable de una zona, se requerirá para aprobarla la previsión de los mayores espacios libres que requiera el aumento de la densidad de población”, precepto que generó una doctrina jurisprudencial que, en el aspecto que aquí nos interesa, vino a relativizar la importancia del hecho de que se cumplieran los estándares legales, pues lo importante en tales casos es que se mantuvieran las proporciones de hecho alcanzadas de tal modo que el au- 
mento de densidad de población debía llevar automáticamente aparejado un correlativo aumento de los correspondientes espacios libres, solución ésta que no es sino la expresión de un principio de irrenunciabilidad a las calidades preexistentes de hecho que habrían de regir por encima del mero respeto a los mínimos legales.

No debe merecer duda la aplicabilidad de este principio por vía analógica al precepto del artículo 36 de la LOUA que ha constituido el objeto de estas reflexiones. Y hay que confiar en que el Consejo Consultivo de Andalucía, depositario de una carga tan pesada como la que dicho precepto supone, acierte con la línea interpretativa a seguir; y que para ello sirva, como pequeño grano de arena, esta modesta aportación. Todo sea por la firme defensa de los parques y jardines urbanos de Andalucía, al menos.

Francisco López Menudo 